\title{
Blood Viscosity in Young Male Diabetics with and without Retinopathy
}

\author{
G. D. O. Lowe, J. M. Lowe, M. M. Drummond, S. Reith, J. J. F. Belch, C. M. Kesson, A. Wylie, W. S. Foulds, \\ C. D. Forbes, A. C. MacCuish, and W. G. Manderson \\ University Department of Medicine, Royal Infirmary, Diabetic Units, Royal Infirmary and Southern General Hospital, \\ and University Department of Ophthalmology, Western Infirmary, Glasgow, Scotland
}

\begin{abstract}
Summary. Blood viscosity (shear rates $100 \mathrm{~s}^{-1}$ and $0.94 \mathrm{~s}^{-1}$ ) and several of its major determinants (haematocrit, plasma fibrinogen and plasma viscosity) have been measured in 38 male insulin-treated diabetics, aged $18-50$ years, and in 38 non-diabetic control subjects matched for age and smoking habit. Diabetics without fundoscopic retinopathy $(n=20)$ had higher mean blood viscosity than controls at the high shear rate $(7.07 \mathrm{cP}$ vs $6.75 \mathrm{cP}, \mathrm{p}<0.05)$ and the low shear rate $(21.2 \mathrm{cP}$ vs $18.7 \mathrm{cP}, \mathrm{p}<0.025)$. These differences persisted after correction of blood viscosity to a standard haematocrit, and were associated with increased plasma viscosity $(1.41 \mathrm{cP}$ vs $1.34 \mathrm{cP}$, $\mathrm{p}<0.025)$ and plasma fibrinogen $(2.9 \mathrm{~g} / \mathrm{L}$ vs. $2.5 \mathrm{~g} /$ $\mathrm{L}, \mathrm{p}<0.025)$. Diabetics with retinopathy $(\mathrm{n}=18)$ had higher mean blood viscosity than diabetics without retinopathy at the high shear rate $(7.53 \mathrm{cP}$ vs $7.07 \mathrm{cP}, \mathrm{p}<0.05)$ and the low shear rate $(24.3 \mathrm{cP}$ vs. $21.2 \mathrm{cP}, \mathrm{p}<0.05$ ), associated with a higher haematocrit $(p<0.05)$. Blood viscosity and haematocrit correlated with the duration of diabetes $(\mathrm{r}>0.32, \mathrm{p}<0.05)$.
\end{abstract}

Key words: Retinopathy, insulin treated diabetes, blood viscosity, plasma viscosity, haematocrit, fibrinogen.

Increased blood viscosity in diabetics was first described by Skovborg and co-workers [1], and has been confirmed in some studies [2-5] but not others [6-8]. These studies have mostly been performed on older patients, in whom interpretation of viscosity data is complicated by heterogeneity of the diabetes, multiple drug therapy, and multiple pathology including atherosclerosis, which is itself associated with increased blood viscosity $[9,10]$. Previous studies have also ignored the effects on viscosity of smoking [11], menstruation [12] and renal impairment [13]. In two studies $[4,5]$ viscosity was related to the presence or absence of retinopathy, but the type of retinopathy (background or proliferative) was not considered.

We have therefore attempted to clarify the role of blood viscosity and its major determinants (haematocrit, plasma fibrinogen, and plasma viscosity) in diabetes and diabetic retinopathy, by studying young insulin-treated male diabetics, with normal urea and creatinine levels, who were otherwise healthy and on no medication. Results have been compared with a group of normal males matched for age and smoking habit.

\section{Materials and Methods}

\section{Subjects}

Thirty-eight insulin-treated, juvenile-onset male diabetics, aged $18-50$ years, who were attending one of two diabetic clinics, were studied. Clinical and biochemical data are given in Table 1. All were healthy apart from diabetes and its complications, and all were within the range $80-120$ percent of ideal body weight. None were taking medication other than insulin, and none had an elevated plasma urea $(>7.0 \mathrm{mmol} / \mathrm{L})$ or creatinine $(>115 \mu \mathrm{mol} / \mathrm{L})$. Diabetic control was assessed as adequate (no oppressive symptoms, most home urine sugar tests $0 .-0.5$ per cent, most clinic plasma glucose levels less than $12 \mathrm{mmol} / \mathrm{L}$, and no hospital admissions in the previous year) or poor (failure to satisfy any of the above criteria). Clinical evidence of retinopathy (fundoscopy of both eyes with pupils dilated), peripheral neuropathy (absent ankle jerks or loss of distal vibration sense), ischaemic heart disease (history of angina or myocardial infarction, or ischaemic changes on resting electro-cardiogram), cerebral ischaemia (history of transient attacks or completed stroke), and peripheral ischaemia (history of claudication or absent foot pulses) was recorded. Proteinuria was measured by Labstix (Ames Co.). 
Table 1. Clinical and biochemical features of subjects studied

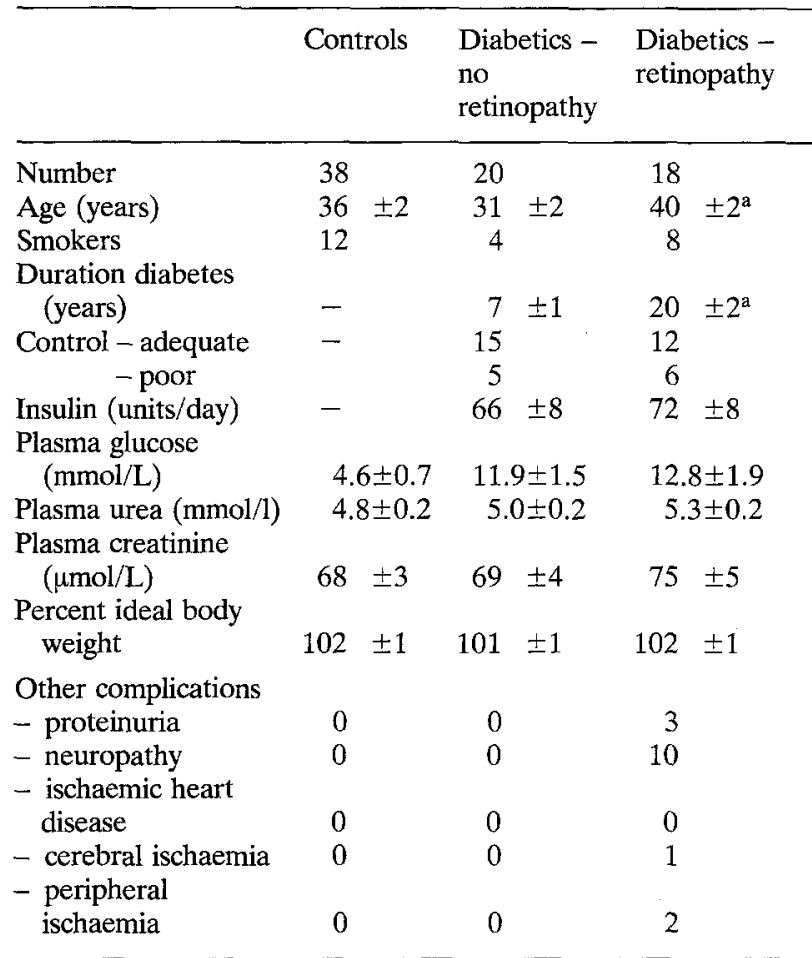

Results are given as mean \pm SEM

${ }^{a}$ Difference from diabetics without retinopathy significant $(\mathrm{p}<0.01)$

For definitions of control and complications, see Methods Section

Retinopathy was classified as background (haemorrhages, exudates or micro-aneurysms, without evidence of proliferative retinopathy) or proliferative (neovascularisation). Fluorescein angiography had previously been performed if clinically indicated (suspected ischaemic or proliferative retinopathy) in 14 of the 18 patients with retinopathy, of whom 9 had confirmed proliferative changes.

For each diabetic we studied a healthy male control subject, matched for age (within two years) and presence or absence of regular cigarette smoking. Controls were selected from hospital staff, or patients admitted to hospital prior to elective minor surgery. None had a personal or family history of diabetes, evidence of vascular disease, or glycosuria. All subjects gave informed consent to the study.

\section{Blood Studies}

Study 1. A venous sample was obtained from resting subjects between 10 a. $\mathrm{m}$. and $1 \mathrm{p}$. m. Subjects were not fasted, as even large fatty meals have no effect on blood or plasma viscosity [14] and as there is no correlation between viscosity and lipid fractions [10]. Plasma glucose was measured in a Beckman Analyser and plasma urea and creatinine in a Technicon Autoanalyser. Fibrinogen was measured in citrated plasma by a thrombin time method [15] using a Dade Fibrometer and standards. Blood was anticoagulated with edetic acid (EDTA: $1 \mathrm{~g} / \mathrm{L}$ ) for estimation of haematocrit (Hawksley micro-haematocrit, $13000 \mathrm{~g}$ for $5 \mathrm{~min}$.), plasma viscosity (BS M3 capillary viscometer, $37^{\circ} \mathrm{C}$ ) and blood viscosity, which was measured in a rotational viscometer $[16]$ at $37^{\circ} \mathrm{C}$, at a high shear rate $\left(100 \mathrm{~s}^{-1}\right)$.
Study 2. In 28 of the diabetic subjects and 28 controls, a second blood sample was taken for measurement of blood viscosity at a low shear rate $\left(0.94 \mathrm{~s}^{-1}\right)$ in a Contraves LS 30 rotational viscometer.

\section{Reproducibility}

The coefficients of variation for our viscosity measurements are plasma viscosity $1 \%$; blood viscosity $\left(100 \mathrm{~s}^{-1}\right), 2 \%$; and blood viscosity $\left(0.94 \mathrm{~s}^{-1}\right), 3 \%$.

\section{Statistical Analysis}

Differences in means of variables were analysed by " $t$ " test, and correlations determined by the method of least squares. Values are given as mean \pm standard error of the mean (SEM).

\section{Results}

\section{Clinical and Biochemical Variables (Table 1)}

The 18 diabetics with retinopathy were older $(\mathrm{p}<0.01)$ and had a longer duration of diabetes $(p<0.01)$ than the 20 diabetics without retinopathy. No patient without retinopathy had clinical evidence of other complications, whereas other complications were present in 5 of the 9 patients with background retinopathy, and all of the 9 patients with proliferative retinopathy. There were no significant differences between diabetic groups in the prevalence of cigarette smoking or poor diabetic control, or in the mean levels of insulin dose or plasma glucose, urea or creatinine.

\section{Blood Viscosity and Haematocrit (Table 2)}

Diabetics without retinopathy had a higher mean blood viscosity than matched controls at shear rate $100 \mathrm{~s}^{-1}(\mathrm{p}<0,05)$. This difference was more marked at shear rate $0.94 \mathrm{~s}^{-1}(\mathrm{p}<0.025)$. Mean haematocrit was not significantly higher in diabetics without retinopathy.

Diabetics with retinopathy had a higher mean blood viscosity than matched controls at $100 \mathrm{~s}^{-1}(\mathrm{p}<0.01)$ and again this difference was more marked at $0.94 \mathrm{~s}^{-1}(\mathrm{p}<0.001)$. Patients with retinopathy also had higher haematocrits than matched controls ( $p<$ 0.05 ). Blood viscosity (at both shear rates) and haematocrit were higher in diabetics with retinopathy compared to diabetics without retinopathy $(\mathrm{p}<$ $0.05)$. There was a linear correlation between haematocrit and blood viscosity at both shear rates $(\mathrm{r}=0.7, \mathrm{p}<0.001)$ in both diabetics and controls. 
Table 2. Blood viscosity and its determinants in diabetics and controls

\begin{tabular}{|c|c|c|c|}
\hline & Controls & $\begin{array}{l}\text { Diabetics - } \\
\text { no retinopathy }\end{array}$ & $\begin{array}{l}\text { Diabetics - } \\
\text { retinopathy }\end{array}$ \\
\hline \multicolumn{4}{|l|}{ Study 1} \\
\hline Number & 38 & 20 & 18 \\
\hline Blood viscosity, $100 \mathrm{~s}^{-1}(\mathrm{cP})$ & $6.75 \pm 0.08$ & $7.07 \pm 0.14^{\mathrm{a}}$ & $7.53 \pm 0.17^{c}$ \\
\hline Haematocrit $(\%)$ & $44.8 \pm 0.4$ & $44.9 \pm 0.7$ & $47.3 \pm 0.9^{\mathrm{a}}$ \\
\hline Corrected blood viscosity (cP) & $6.78 \pm 0.05$ & $7.08 \pm 0.12^{\mathrm{a}}$ & $7.19 \pm 0.11^{c}$ \\
\hline Fibrinogen $(g / L)$ & $2.50 \pm 0.09$ & $2.90 \pm 0.14^{b}$ & $3.45 \pm 0.29^{\mathrm{b}}$ \\
\hline Plasma viscosity (cP) & $1.34 \pm 0.01$ & $1.41 \pm 0.02^{b}$ & $1.41 \pm 0.03^{b}$ \\
\hline \multicolumn{4}{|l|}{ Study 2} \\
\hline Number & 28 & 14 & 14 \\
\hline Blood viscosity, $0.94 \mathrm{~s}^{-1}$ (cP) & $18.7 \pm 0.6$ & $21.2 \pm 0.8^{\mathrm{b}}$ & $24.3 \pm 1.1^{\mathrm{c}}$ \\
\hline Haematocrit $(\%)$ & $45.2 \pm 0.6$ & $45.7 \pm 1.0$ & $48.5 \pm 1.0^{c}$ \\
\hline Corrected blood viscosity $(\mathrm{cP})$ & $18.6 \pm 0.5$ & $20.7 \pm 0.8^{b}$ & $21.7 \pm 0.8^{c}$ \\
\hline Fibrinogen $(\mathrm{g} / \mathrm{L})$ & $2.58 \pm 0.09$ & $2.99 \pm 0.17^{\mathrm{a}}$ & $3.11 \pm 0.19^{\mathrm{c}}$ \\
\hline
\end{tabular}

Results are given as mean \pm SEM. $\mathrm{cP}=$ centipoise. Corrected blood viscosity $=$ blood viscosity corrected to standard haematocrit of $45 \%$ Subscripts indicate significant difference from matched controls: ${ }^{a} p<0.05,{ }^{b} p<0.025,{ }^{c} p<0.01$

\section{Corrected Blood Viscosity, Plasma Viscosity and Fibrinogen (Table 2)}

Using the regression equations obtained from correlation of blood viscosity and haematocrit, blood viscosity was corrected to a standard haematocrit of $45 \%$. Both groups of diabetics had higher mean corrected blood viscosity than matched controls, the differences being greater at $0.94 \mathrm{~s}^{-1}(\mathrm{p}<0.025)$ than $100 \mathrm{~s}^{-1}(\mathrm{p}<0.05)$. Plasma viscosity and fibrinogen were also increased in both groups of diabetics compared to controls $(p<0.05)$. Corrected blood viscosity, plasma viscosity and fibrinogen were not significantly higher in diabetics with retinopathy than in diabetics without retinopathy. Significant linear correlations were obtained when fibrinogen was compared with corrected blood viscosity at both shear rates $(\mathrm{r}=0.4, \mathrm{p}<0.001)$ and with plasma viscosity $(\mathrm{r}=0.5, \mathrm{p}<0.001)$

\section{Viscosity and Type of Retinopathy}

There were no significant differences in blood viscosity or its determinants when the background retinopathy group were compared to the proliferative retinopathy group. However patients with proliferative retinopathy had the highest mean levels of haematocrit (48 \pm SEM 1\%), high shear blood viscosity $(7.68 \pm 0.25 \mathrm{cP})$ and low shear blood viscosity $(24.8 \pm 1.4 \mathrm{cP})$, all significantly higher than in diabetics without retinopathy $(\mathrm{p}<0.05)$. Patients with background retinopathy did not have significantly higher mean haematocrit $(46.4 \pm 1.7 \%)$, high shear blood viscosity $(7.35 \pm 0.25 \mathrm{cP})$ or low shear blood viscosity $(23.8 \pm 1.4 \mathrm{cP})$ than diabetics without retinopathy.

\section{Viscosity and Duration of Diabetes}

Blood viscosity and haematocrit each correlated with the duration of diabetes in the whole group of 38 diabetics $(r>0.32, p<0.05)$ and in the subgroup of 20 diabetics without retinopathy $(\mathrm{r}>0.49$, $\mathrm{p}<0.05$ ). There were no significant correlations between duration of diabetes and fibrinogen $(\mathrm{r}=0.2)$ or corrected blood viscosity $(\mathrm{r}=0.1)$. Viscosity and its determinants did not correlate significantly with insulin dosage or plasma levels of glucose, urea or creatinine.

\section{Discussion}

We have shown that young male diabetics have increased blood viscosity, at both high and low shear rates, compared to non-diabetics, and that this is present before the onset of clinically detectable retinopathy or other vascular complications. The increased viscosity is not due to an increase in haematocrit, for it persists after correction for haematocrit differences between groups. The increased plasma viscosity suggests that plasma proteins are largely responsible, and increased plasma fibrinogen appears to be one of these proteins. However, increases in other globulins $[1,5]$ or reduced red cell deformability [17] may also play a part in the viscosity elevation. 
We have found, as have others $[4,5]$ that the increase in blood viscosity is greater at a low shear rate $\left(0.94 \mathrm{~s}^{-1}\right)$ than at a high shear rate $\left(100 \mathrm{~s}^{-1}\right)$. This may be of clinical significance, as low shear rates may be encountered in the post-capillary venules, where early retinal changes are found in diabetics $[4$, 5]. The increase in high shear blood viscosity is of the same order as the increase in plasma viscosity. The additional increase in blood viscosity at the low shear rate may result from the well-known increase in red cell aggregation observed in low shear systems, which is associated with increased fibrinogen levels.

Most previous studies have found increased blood viscosity [1-5], plasma or serum viscosity $[3,18,19]$ and plasma fibrinogen $[1,4-8]$ in older diabetics. Our demonstration that these abnormalities are present in young diabetics before the onset of retinopathy and other complications, is consistent with the hypothesis that they may play a part in the pathogenesis of such complications, as originally suggested by Ditzel and Skovborg [20]. Increased viscosity slows retinal blood flow [21], and it has been suggested that stagnation of blood flow in the microcirculation might result in local hypoxia, lactic acidosis, and hence microvascular damage [22]. These changes may lead to further increases in viscosity and a positive feedback cycle [23]. Retinopathy similar to that found in diabetics is associated with other conditions [24] in some of which there is increased blood viscosity [5]. Atherosclerosis is also associated with increased blood viscosity $[9,10]$, and increased viscosity is found in other groups of subjects at increased risk of atherosclerosis such as cigarettesmokers [11], hypertensives [25] and women taking oral contraceptives [26].

We found that diabetics with retinopathy had higher blood viscosity than diabetics without retinopathy. This was largely due to an increased haematocrit, which was significantly higher than in diabetics without retinopathy or in non-diabetics: blood viscosity was not significantly higher in diabetics with retinopathy after correction for the raised haematocrit. Some previous studies have also found that viscosity is higher in diabetics with retinopathy $[4,5]$, but only one other study found an increased haematocrit in such patients [2]. In previous studies the possible effect of renal impairment - which is associated with a reduced haematocrit [13] - was not considered: this effect was minimised in our study by exclusion of patients with elevated plasma urea or creatinine.

The mechanism of the increased haematocrit is unknown: it cannot be explained by differences in smoking [11]. Hyperglycaemia may cause an osmotic diuresis, and hence may lower plasma volume and increase haematocrit: a fall in haematocrit and blood viscosity has been observed after institution of diabetic control [27]. However, in the present study poor control and plasma glucose were not significantly increased in the retinopathy group, and plasma glucose was not correlated with viscosity. As expected, retinopathy was associated with evidence of more widespread microangiopathy (peripheral neuropathy, proteinuria), and it is possible that widespread increased microvascular permeability might lead to reduced plasma volume and hence increased haematocrit [28]. Whatever the mechanism of the high haematocrit in patients with retinopathy, a pathogenetic role cannot be excluded: increased haematocrit is associated with slowed retinal circulation [21].

Finally, we have correlated blood viscosity, and also haematocrit, with the duration of diabetes. These correlations are not due entirely to the fact that diabetics with retinopathy, in whom viscosity and haematocrit were highest, had, as expected, a longer duration of diabetes. The correlations were still significant in the group of patients without retinopathy. Further work is required to establish the pathogenetic significance of blood viscosity and its determinants in diabetics, and to establish whether reduction of viscosity might prevent vascular complications.

Acknowledgements. We thank Dr. J. T. Ireland and Dr. J. C. Barbenel for their assistance.

\section{References}

1. Skovborg F, Nielsen AV, Schlichtkrull J, Ditzel J (1966) Blood-viscosity in diabetic patients. Lancet I:129-131

2. Labib MAM, Higazi AM, El-Ebrashy N, El-Ashmaway S, Madkour M K, Barhooma G A (1971) Studies on diabetic retinal vascular changes with special reference to blood coagulation and viscosity. Bull Ophthalmol Soc Egypt 64:457-482

3. Isogai Y, Iida A, Michizuki K, Abe M (1976) Hemorheological studies on the pathogenesis of diabetic microangiopathy. Thromb Res 8 [Suppl II]: 17-24

4. Hoare EM, Barnes A J, Dormandy J A (1976) Abnormal blood viscosity in diabetes mellitus and retinopathy. Biorheology $13: 21-25$

5. Barnes A J, Locke P, Scudder P R, Dormandy TL, Dormandy J A, Slack J (1977) Is hyperviscosity a treatable component of diabetic microcirculatory disease? Lancet II : 789-791

6. Ditzel J (1968) Whole-blood viscosity and related components in diabetes mellitus. Dan Med Bull 15:49-53

7. Bollinger A, Berchtold P, Berger W (1968) Untersuchungen der Blutviscosität bei Diabetikern. Praxis 58:1104-1107

8. Mosora N, Baciu T, Vincze J (1972) The viscosity of the serum, haematocrit and fibrinogen in diabetes mellitus and their relationship with diabetes mellitus. Diabetologia 8:59

9. Mayer GA (1964) Blood viscosity in healthy subjects and patients with coronary heart disease. Can Med Assoc J 91:951-954 
10. Dormandy J A, Hoare E, Colley J, Arrowsmith DE, Dormandy TL (1973) Clinical, haemodynamic, rheological, and biochemical findings in 126 patients with intermittent claudication. Br Med J IV:576-581

11. Dintenfass L (1975) Elevation of blood viscosity, aggregation of red cells, haematocrit values and fibrinogen levels in cigarette smokers. Med J Aust 1:617-620

12. Dintenfass L, Yu J S (1968) Changes in the blood viscosity and the consistency of artificial thrombi in 17-year-old girls during the menstrual cycle. Med J Aust 1:181-183

13. de Wardener HE (1973) The kidney. Churchill Livingstone, Edinburgh London, p 115-117

14. Charm SE, McComis W, Tejada C, Kurland G (1963) Effect of a fatty meal on whole blood and plasma viscosity. J Appl Physiol 18:1217-1220

15. Clauss A (1957) Gerinnungsphysiologische Schnellmethode zur Bestimmung des Fibrinogens. Acta Haematol (Basel) $17: 237-246$

16. Dintenfass L (1969) A co-axial rhombo-spheroid viscometer: a further development of the cone-in-cone viscometer. Biorheology 6:33-36

17. Juhan I, Bayle J, Vague P, Juhan C (1978) Deformabilite des hematies chez les diabetiques. Nouv Presse Med 7:759

18. Cogan D G, Merola L, Laibson PR (1961) Blood viscosity, serum hexosamine and diabetic retinopathy. Diabetes 10:393-395

19. McMillan DE (1974) Disturbance of serum viscosity in diabetes mellitus. J Clin Invest 53:1071-1079

20. Ditzel J, Skovborg F (1968) Hemorheological investigations in relation to diabetes mellitus and its angiopathy. In: Hemorheology, Proceedings of the First International Conference, Reykjavik, 1966. Pergamon, Oxford New York, p 751-761
21. Hume R, Begg IS (1969) The relationship of blood volume and blood viscosity to retinal vessel size and circulation time in polycythaemia. In: Cant JS (ed) The William MacKenzie Centenary Symposium on the Ocular Circulation in Health and Disease. Kimpton, London, p 158-169

22. Ashton N (1963) Studies of the retinal capillaries in relation to diabetic and other retinopathies. $\mathrm{Br} \mathrm{J}$ Ophthalmol 47: $521-538$

23. Dintenfass L (1976) Rheology of blood in diagnostic and preventive medicine. Butterworths, London Boston, p 26-36

24. Ashton N (1951) Retinal micro-aneurysms in the non-diabetic subject. Br J Ophthalmol 35:189-212

25. Tibblin G, Bergentz SE, Djure J, Wilhemsen L (1966) Haematocrit, plasma protein, plasma volume, and viscosity in early hypertensive disease. Am Heart J 72:165-176

26. Aronson HB, Magora F, Schenker J G (1971) Effect of oral contraceptives on blood viscosity. Am J Obstet Gynecol 110:997-1001

27. Barnes A J, Locke P, Dormandy TL, Dormandy J A (1977) Blood viscosity and metabolic control in diabetes mellitus. Clin Sci Mol Med 52:24-25

28. Langer L, Bergentz SE, Bjure J, Fagerberg SE (1971) The effect of exercise on haematocrit, plasma volume and viscosity in diabetes mellitus. Diabetologia $7: 29-33$

Received: June 30, 1979, and in revised form: November 23, 1979

Dr. G. D. O. Lowe

University Department of Medicine

Royal Infirmary

86 Castle Street

Glasgow G4 OSF, Scotland 